\title{
Avaliação da transmissão da Brachyspira pilosicoli através da infecção experimental em pintos de um dia*
}

\author{
Assessment of the transmission of Brachyspira pilosicoli infection using a one-day old chick model \\ Fabiana Paulovich ${ }^{1}$, Sandra Maria Borowski ${ }^{2}$, David Driemeier ${ }^{3}$, Luis Eduardo Razia ${ }^{1}$, Tania Allen \\ Coutinho ${ }^{2}$, Aline Beatriz Heinen Prates ${ }^{1}$, Caroline Argenta Pescador ${ }^{3}$, André Mendes Ribeiro Correa ${ }^{3}$ \\ \& David Emilio Santos Neves de Barcellos ${ }^{1}$
}

\begin{abstract}
RESUMO
A Brachyspira pilosicoli é uma causa reconhecida de diarréia em diversas espécies animais e no homem. A transmissão ocorre principalmente pelas fezes, alimentos ou água contaminada. A bactéria tem boa capacidade de sobrevivência no meio ambiente, o que gera amplas oportunidades de transmissão. Este trabalho avaliou a capacidade de difusão horizontal de diferentes cepas de B. pilosicoli. Foram usadas 2 cepas de referência e 19 cepas de campo da bactéria, isoladas de casos de diarréia em suínos no Estado do Rio Grande do Sul, usando um modelo de infecção oral de pintos de um dia. Para cada cepa, 4 animais foram inoculados com uma suspensão de bactérias vivas e mantidos em gaiola com outros dois animais não inoculados (contatos). Decorridos 21 dias foram sacrificados e os cecos examinados por histopatologia, através da imuno-histoquímica. Foi observado que 73,68\% das cepas de B. pilosicoli foram capazes de colonizar o epitélio do ceco. Houve diferenças no tipo de colonização, ocorrendo aderência contínua, focal ou presença de bactérias livres na luz intestinal. Com relação à capacidade de transmissão horizontal da infecção por B. pilosicoli, 57,89\% das cepas foram capazes de aderir e/ou serem detectadas livres na luz intestinal dos animais contatos. A conclusão desse experimento foi de que algumas das cepas de campo mostraram alta capacidade de difusão horizontal.
\end{abstract}

Descritores: Brachyspira spp., Brachyspira pilosicoli, Colite Espiroquetal, Imuno-histoquímica, Transmissão Horizontal.

\begin{abstract}
Brachyspira pilosicoli is a recognized agent of diarrhea in several animal species and man. The transmission occurs specially through contact with feces, food or contaminated water. It shows a good survival in the environment, and this gives good opportunities for transmission. The present work assessed the capacity of horizontal spread of different strains of B. pilosicoli. Two reference and 19 field strains of the bacteria were used, isolated from cases of diarrhea in pigs in the State of Rio Grande do Sul, Brazil, applying an one-day old chick model of infection. For each strain, 4 chicks were inoculated with a live bacterial culture and kept in a cage with other two non-inoculated chicks. After 21 days, they were submitted to euthanasia and the cecum examined histopathologically using immuno-histochemistry. It was observed that $73.68 \%$ of the B. pilosicoli strains were able to colonize the cecal epithelium. There was differences in the type of colonization, occurring continuous adhesion, focal adhesion or free bacteria in the intestinal lumen. Regarding the capacity of horizontal transmission of B. pilosicoli infection, $57.89 \%$ of the strains were able to adhere or were detected in the intestinal lumen of contact animals. The conclusion of the present work was that some field strains presented high capacity of horizontal diffusion.
\end{abstract}

Key words: Brachyspira spp., Brachyspira pilosicoli, Spirochetal Colitis, Immunohistochemistry, Horizontal Transmission.

\footnotetext{
"Trabalho originado da Dissertação de Mestrado [(Programa de Pós-graduação em Ciências Veterinárias (PPGCV) - UFRGS)] do primeiro autor. ${ }^{1}$ Setor de Suínos, Faculdade de Veterinária - UFRGS, Porto Alegre, RS. ${ }^{2}$ Centro de Pesquisas Veterinárias Desidério Finamor (CPVDF) - FEPAGRO, Eldorado do Sul, RS, ${ }^{3}$ Setor de Patologia Veterinária, DPCV/FAVET-UFRGS. CORRESPONDÊNCIA: D.E.S.N. Barcellos [davbarce@terra.com.br ; FAX: 513316 7305].
} 


\section{INTRODUÇÃO}

A Brachyspira pilosicoli é o agente de uma forma de diarréia infecciosa em suínos denominada colite espiroquetal (CE), que afeta principalmente leitões nas fases de crescimento e terminação. A transmissão ocorre de leitão a leitão pelas fezes, alimentos ou água contaminada [13]. Inexiste, entretanto, uma comprovação mais direta para validar essa afirmação. A sobrevivência do agente no ambiente foi 14 dias a $4^{\circ} \mathrm{C}$ e por até 7 dias a $24^{\circ} \mathrm{C}$ [2]. Essa longa sobrevivência gera amplas oportunidades de transmissão de bactérias no ambiente em que os suínos são criados, principalmente nos casos de falhas de limpeza e desinfecção.

Existem poucas técnicas disponíveis para a avaliação da patogenicidade experimental da $B$. pilosicoli. A inoculação de suínos mostra resultados insatisfatórios, mas a infecção pode ser reproduzida consistentemente usando um modelo de infecção em pintos de um dia $[7,10,14,15]$.

O objetivo deste trabalho foi o de avaliar a capacidade infectante de cepas da bactéria isoladas anteriormente de granjas no Estado do Rio Grande do Sul [2], usando o modelo de infecção de pinto para avaliação da colonização cecal. Também foi estudada a capacidade da transmissão horizontal da infecção, através da manutenção de pintos inoculados e contatos não inoculados na mesma gaiola.

\section{MATERIAIS E MÉTODOS}

Foram usados 132 pintos de um dia de vida, divididos em 22 lotes de 6. Em função da mistura acidental de dois grupos (inoculados com as cepas SIPV $42 \mathrm{e}$ 43), o experimento final foi realizado com 20 lotes de 6 pintos e um $21^{\circ}$ grupo com 12 pintos. De cada grupo experimental com 6 animais, 4 foram inoculados com cada uma das cepas de B. pilosicoli e 2 mantidos como contatos, não inoculados. Os contatos foram alojados na mesma gaiola dos desafiados e marcados individualmente, para permitir a diferenciação. Cada grupo experimental foi mantido em gaiola individual, sem contato com os leitões das outras gaiolas. A sala onde foram alojados possuía aporte de ar filtrado e condicionamento ambiental, mantendo uma temperatura média de 35 graus centígrados e umidade média de $85 \%$. Vinte e quatro horas antes de introduzir os animais, a sala e a ante-sala foram esterilizadas.
Nas primeiras 24 horas após o desafio, os pintos não receberam ração ou água. A seguir, foi fornecida ração não comercial, sem antimicrobianos. A água de bebida e a comida estiveram disponíveis ad libitum durante o experimento. Os pintos foram examinados diariamente, com avaliação visual e análise da consistência das fezes, segundo os critérios sugeridos por Barcellos \& Sobestiansky [4]. As gaiolas foram limpas apenas no final do experimento porque a quantidade de fezes acumuladas não justificava a limpeza periódica e para simular as condições em que os animais são mantidos nas granjas. Para infectar os pintos, foram usadas as seguintes cepas de referência, obtidas através do Dr. Gerald Duhamel, Department of Veterinary Clinical Studies, Lincoln, Nebraska, USA:

P43/6/78, ATCC 51139, cepa de referência de $B$. pilosicoli [12];

SP16, ATCC 49776, isolado humano, proveniente dos Estados Unidos da América [6].

Foram usadas também as seguintes amostras de campo, que haviam sido isoladas de suínos com diarréia da região sul do Brasil [3] e estavam disponíveis na Faculdade de Veterinária da UFRGS: SIPV 1, 8, 9, 12, 13, $14,15,16,18,19,20,22$, 23, 36, 37, 38, 39, 40, 42 e 43.

As cepas de referência apresentavam um número não discriminado de passagens e as de campo entre 3 a 7 passagens em meios artificiais de cultivo. Após ressuspensão das bactérias liofilizadas com solução salina, foram multiplicadas em agitação (300 rpm), num meio líquido pré-reduzido esterilizado (Meio PRAS), [9] a $37^{\circ} \mathrm{C}$, por 5 dias. A titulação do inóculo foi realizada através da contagem das células bacterianas em câmara de Neubauer. Um volume de $0,8 \mathrm{~mL}$ de suspensão contendo $1 \times 10^{8}$ bactérias $/ \mathrm{mL}$ foi fornecido oralmente a 4 de 6 pintos de cada grupo no início do experimento por 3 vezes, a cada 3 horas. Os 2 animais remanescentes de cada grupo foram mantidos como contatos, inoculados simultaneamente com um volume igual de meio de cultivo estéril.

Vinte e um dias após a inoculação, os animais foram sacrificados, segundo normas aceitas de eutanásia. Foi retirada a porção proximal, medial e distal do ceco fragmentos para cortes para análise histopatológica, usando a imuno-histoquímica. Os materiais foram imediatamente imersos numa solução de 
Paulovich F., Borowsky S.M., Driemeier D., Razia L.E., Coutinho T.A., Prates A.B.H., Pescador C.A., Correa A.M.R. \& Barcellos D.E.S.N.2004. Avaliação da transmissão da Brachyspira pilosicoli através da infecção... Acta Scientiae Veterinariae. 32:19-23.

formalina tamponada a $10 \%$ por um mínimo de um dia, antes de realizar-se as desidratações em concentrações crescentes de álcool e as demais etapas do processamento histológico [11]. A partir dos blocos, os tecidos foram cortados em micrótomo numa espessura de aproximadamente $5 \mu \mathrm{m}$ e montados sobre uma lâmina de microscopia. O soro hiperimune policlonal usado para a técnica imuno-histoquímica foi produzido [5] através da hiperimunização de coelhos com a cepa $\mathrm{P} 43 / 6 / 78$. O método imunohistoquímico usado foi o da Streptavidina Biotina Marcada ${ }^{1}$ (LSAB)[8]. A leitura foi feita em microscópio ótico, com 400 aumentos.

\section{RESULTADOS}

\section{Achados macroscópicos}

Durante o experimento, os animais se apresentaram clinicamente normais e as fezes, não mostraram alterações significativas de consistência. No final, alguns pintos estavam desidratados, mas sem diarréia. Na necropsia dos inoculados e contatos, a única lesão detectada foi escassa hiperemia e algumas sufusões na parte média e distal do ceco, em dois pintos.

\section{Achados microscópicos}

Um resumo dos resultados com relação à colonização bacteriana do ceco e para a presença de Brachyspira spp. na luz intestinal consta da Tabela 1.

Pode ser observado que $73,68 \%$ (14/19) das cepas colonizaram o epitélio do ceco dos animais inoculados com B. pilosicoli e $57,89 \%$ (11/19) das cepas colonizaram os contatos. Houve diferenças no tipo de colonização, ocorrendo aderência contínua, focal ou presença de bactérias livres na luz intestinal em 3 cepas.

Apresentaram resultado negativo para a colonização epitelial 6 entre as 21 cepas testadas $(23,52 \%)$, sendo as 2 cepas de referência e as lâminas referentes a 4 entre as 19 cepas de campo (SIPV 19,36,38 e 43). A colonização do epitélio intestinal esteve presente em todas as cepas restantes, de maneira focal ou ao longo de toda a borda epitelial. No caso das cepas SIPV 8, além da colonização da superfície epitelial, a bactéria estava presente na luz intestinal. Na cepa 43, não foi observada coloniza-
Tabela 1. Resultados dos exames histopatológicos, avaliando a colonização do ceco de pintos e a presença de Brachyspira pilosicoli livres na luz intestinal.

\begin{tabular}{|c|c|c|}
\hline Cepa Bacteriana & Inoculados & Contatos \\
\hline $\mathrm{P} 43 / 6 / 78$ & - & - \\
\hline SP16 & - & - \\
\hline SIPV 1 & + & + \\
\hline SIPV 8 & + & + \\
\hline SIPV 9 & + & - \\
\hline SIPV 12 & + & - \\
\hline SIPV 13 & + & + \\
\hline SIPV 14 & + & + \\
\hline SIPV 15 & + & - \\
\hline SIPV 16 & + & + \\
\hline SIPV 18 & + & - \\
\hline SIPV 19 & - & - \\
\hline SIPV 20 & + & -1 \\
\hline SIPV 22 & + & + \\
\hline SIPV 23 & -1 & + \\
\hline SIPV 36 & - & - \\
\hline SIPV 37 & + & + \\
\hline SIPV 38 & - & - \\
\hline SIPV 39 & + & - \\
\hline SIPV 40/42 & + & + \\
\hline SIPV 43 & - & -1 \\
\hline TOTAL +2 & $14 / 19(73,68 \%)$ & $11 / 19(57,89 \%)$ \\
\hline \multicolumn{3}{|c|}{$\begin{array}{l}\text { Aderência presente em pelo menos } 1 \text { entre os } 4 \text { pintos inoculados, e entre } \\
\text { oelo menos } 1 \text { entre os } 2 \text { controles; ' Ausência de aderência nos } 4 \text { pintos } \\
\text { noculados ou nos } 2 \text { controles; }{ }^{1} \text { Aderência negativa, mas presença de } \\
\text { espiroquetas livres na luz intestinal; }{ }^{2} \text { Totalização para as } 19 \text { amostras de } \\
\text { campo, desconsiderando as cepas controle P43/6/78 e SP16 }\end{array}$} \\
\hline
\end{tabular}

ção superficial, mas espiroquetas foram encontradas livres na luz intestinal.

\section{DISCUSSÃO}

Nas diversas espécies animais, a transmissão da infecção com B. pilosicoli ocorre, principalmente, através da via fecal-oral [1]. No caso atual, como forma de avaliar o grau de infecção cruzada (transmissão horizontal), foi usado um modelo experimental que en- 
volveu o alojamento na mesma gaiola de pintos inoculados e contatos não inoculados. Usando a técnica da imuno-histoquímica, foi demonstrada a infecção cruzada (avaliada pela colonização intestinal e/ou presença de espiroquetas livres na luz intestinal) em 11/19 $(57,89 \%)$ entre as cepas avaliadas (SIPV 1, 8, 13,14,16,20,22,23,37, 40/42 e 43). Em duas dessas amostras (SIPV 20 e 43), observou-se apenas a presença de bactérias livres na luz intestinal. O piso das gaiolas era de telado de arame com furos quadrados, totalmente vazado, drenando líquidos e sólidos e proporcionando um ambiente de baixa contaminação fecal aos pintos. Mesmo nessa situação observou-se que a infecção ocorreu de forma maciça, o que sugeriu uma alta capacidade infectante para pintos das amostras de B. pilosicoli de origem suína usadas no experimento.

Houve diferença no grau das lesões histológicas para as distintas cepas. Especificamente para as cepas SIPV 9 e 13, notou-se uma reação não presente nas outras amostras. Consistia de maciça aderência da bactéria ao epitélio do ceco e das criptas. Ao mesmo tempo, foi observada uma forte resposta inflamatória na mucosa e na lâmina própria, com presença de heterófilos e macrófagos. Para as outras cepas, os achados microscópicos ficaram restritos à aderência da bactéria, com ocorrência eventual de uma ou outra entre as lesões histológicas que estiveram presentes na totalidade no caso anterior. Um achado em todos os cortes positivos foi hiperplasia e hipertrofia do epitélio intestinal e das criptas.

A amostra padrão da espécie (P43/6/78) e o isolado de origem humana (SP16) não aderiram e não induziram a uma reação inflamatória. Não foram encontrados registros do uso dessas cepas no modelo adotado por nós, o que dificultou a análise do resultado. De outra parte, essas cepas sofreram um elevado número de sub-cultivos em diversos locais. Nessas condições, bactérias podem perder determinados fatores de virulência e apresentar diminuição na capacidade patogênica.

Lesões macroscópicas foram observadas em apenas $2,3 \%$ dos cecos dos pintos inoculados. Isso demonstrou uma baixa patogenicidade das cepas de
B. pilosicoli para esses animais. De outra parte, a colonização foi detectada em $73,68 \%$ dos animais inoculados e em $57,89 \%$ dos contatos, o que confirmou a alta capacidade do organismo em se associar ao epitélio intestinal sem induzir problemas clínicos. Isso pode ser verificado pela ausência de diarréia, coincidindo com registros anteriores $[6,14]$.

Na observação das lâminas positivas, o achado microscópico mais relevante foi a aderência da bactéria à superfície do epitélio intestinal. Num número menor de lâminas, observou-se também a invasão das glândulas epiteliais, conforme relatado anteriormente $[6,13]$. Uma outra observação desses autores foi uma infreqüente invasão de macrófagos, o que foi confirmado nas nossas observações em três lâminas: cepas SIPV 6,8 e 18.

Com relação à presença de espiroquetas livres na luz intestinal, foi detectada em 3 cepas, sendo que duas de contatos. Pode-se especular que o processamento histopatológico poderia ter causado a presença da bactéria na luz intestinal. Entre os fatores que poderiam explicar essa "descamação" das bactérias aderidas, poderia ser citado o atrito com a navalha e a ação dos álcoois e de outros reativos usados no processamento dos cortes.

\section{CONCLUSÕES}

A imuno-histoquímica mostrou-se sensível para a detecção da Brachyspira pilosicoli no epitélio do ceco dos pintos inoculados. As cepas que foram capazes de colonizar demonstraram diferenças nessa capacidade e em induzir lesões histológicas. Isso poderia sugerir variações no grau de patogenicidade, mas pela ausência dos sintomas característicos da infecção intestinal por Brachyspira spp. em pintos (diarréia), pode-se dizer que houve apenas diferença no grau de infecciosidade. A mistura dos animais contatos com os inoculados nas gaiolas permitiu comprovar a transmissão horizontal pela via fecal-oral em 57, 89\% das cepas avaliadas.

\section{Nota Informativa}

${ }^{1}$ LSAB, Biogen, São Paulo, Brasil. 


\section{REFERÊNCIAS}

1 Barcellos D.E.S.N. 2000. Infecção por Brachyspira spp. em suínos: epidemiologia e caracterização fenotípica e genotípica das espécies. 163 f.Rio de Janeiro, RJ. Tese (Doutorado em Ciências - Microbiologia) - Instituto de Microbiologia, Universidade Federal do Rio de Janeiro.

2 Barcellos D.E.S.N., Mathiesen M.R. \& Duhamel G.E. 2000. Effect of temperature on survival of pathogenic spirochetes in spiked pig feces. In: Proceedings of the 16th International Pig Veterinary Society Congress (Melbourne, Australia). p.44.

3 Barcellos D.E.S.N., Mathiesen M., Uzeda M., Kader I.T.A. \& Duhamel G.E. 2000. Prevalence of Brachyspira species isolated from diarrhoeic pigs in Brazil. The Veterinary Record. 146: 398-403.

4 Barcellos D.E.S.N. \& Sobestiansky J. 2003. J. Atlas de Doenças dos Suínos. Goiânia: Art 3 Ed., 208p.

5 Burrows M.R. \& Lemke R.M. 1981. Identification of Treponema hyodysenteriae by a rapid miccroaglutination test. The Veterinary Record. 108: 187-189.

6 Duhamel G.E. 2001.Comparative pathology and pathogenesis of naturally acquired and experimentally induced colonic spirochetosis. Animal Health Research Reviews.2: 3-17.

7 Dwars R.M., Davelaar F.G. \& Smith H.F. 1992. Infection of broiler chicks (Gallus domesticus) with human intestinal spirochaetes. Avian Pathology. 21: 559-568.

8 Gimeno E.J., Belak K., Massone A.R. \& Ibargoyen G.S. 2002. Técnicas inmunohistoquímicas en patología veterinaria: aspectos teóricos y prácticos. Veterinaria Argentina. 6: 332-339.

9 Kunkle R.A., Harris D.L. \& Kinyon J.M. 1986. Autoclaved liquid medium for propagation of Treponema hyodysenteriae. Journal of Clinical Microbiology. 24: 669-671.

10 Paulovich F. 2003. Avaliação da patogenicidade de amostras de Brachyspira pilosicoli através de técnicas histopatológicas convencionais e por imunohistoquímica. 48 f. Porto Alegre - RS. Dissertação (Mestrado em Ciências Veterinárias) - Programa de Pós-graduação em Ciências Veterinárias, Universidade Federal do Rio Grande do Sul.

11 Prophet E.B. 1992. Fixation. In: Prophet. E B. (Ed.). Laboratory Methods in Histotechnology. Washington D.C.: American Registry of Pathology, pp. 25-28.

12 Taylor D.J, Simmons J.R. \& Laird H.M. 1980. Production of diarrhoea in pigs feeding pure cultures of a spirochete differing from Treponema hyodysenteriae. The Veterinary Record. 106: 326-332.

13 Taylor D.J. \& Trott D.J. 1997. Porcine Intestinal Spirochaetosis and Spirochaetal Colitis. In: Hampson D.J.\& Stanton T.B. (Eds.). Intestinal spirochetes in domestic animals and man. Cambridge: CAB International, pp.211-241.

14 Trott D.J. \& Hampson D.J. 1998. Evaluation of day-old specific pathogen free chicks as an experimental model for pathogenicity testing of intestinal spirochaete species. Journal of Comparative Pathology. 118: 365-381.

15 Trott D.J., McLaren A.J. \& Hampson D.J. 1995. Pathogenicity of human and porcine intestinal spirochetes in day-old specific pathogen free chicks: an animal model for intestinal spirochetosis. Infection and Immunity. 63: 3705-3710. 